\title{
A Novel Poly-N-Epoxy Propyl Carbazole Based Memory Device
}

\author{
Ahmed. N. M. Alahmadi ${ }^{1, *}$ and Khasan S. Karimov ${ }^{2}$ \\ 1 Electrical Engineering Department, Umm-Al-Qura University, Makkah 21955, Saudi Arabia \\ 2 Ghulam Ishaq Khan Institute of Engineering Sciences and Technology, Topi 23640, Khyber Pakhtunkhwa, \\ Pakistan; khasan@giki.edu.pk \\ * Correspondence: anmahmadi@uqu.edu.sa
}

Citation: Alahmadi, A..N.M.;

Karimov, K.S. A Novel Poly-N-Epoxy

Propyl Carbazole Based Memory

Device. Polymers 2021, 13, 1594.

https://doi.org/10.3390/

polym13101594

Academic Editor: Bożena Jarzą̧ek

Received: 10 April 2021

Accepted: 12 May 2021

Published: 15 May 2021

Publisher's Note: MDPI stays neutral with regard to jurisdictional claims in published maps and institutional affiliations.

Copyright: (c) 2021 by the authors. Licensee MDPI, Basel, Switzerland. This article is an open access article distributed under the terms and conditions of the Creative Commons Attribution (CC BY) license (https:// creativecommons.org/licenses/by/ $4.0 /)$.

\begin{abstract}
Generally, polymer-based memory devices store information in a manner distinct from that of silicon-based memory devices. Conventional silicon memory devices store charges as either zero or one for digital information, whereas most polymers store charges by the switching of electrical resistance. For the first time, this study reports that the novel conducting polymer Poly-N-EpoxyPropyl Carbazole (PEPC) can offer effective memory storage behavior. In the current research, the electrical characterization of a single layer memory device (metal/polymer/metal) using PEPC, with or without doping of charge transfer complexes 7,7,8,8-tetra-cyanoquino-dimethane (TCNQ), was investigated. From the current-voltage characteristics, it was found that PEPC shows memory switching effects in both cases (with or without the TCNQ complex). However, in the presence of TCNQ, the PEPC performs faster memory switching at relatively lower voltage and, therefore, a higher $\mathrm{ON}$ and $\mathrm{OFF}$ ratio $\left(\mathrm{I}_{\mathrm{ON}} / \mathrm{I}_{\mathrm{OFF}} \sim 100\right)$ was observed. The outcome of this study may help to further understand the memory switching effects of conducting polymer.
\end{abstract}

Keywords: memory device; organic semiconductors; poly-N-epoxy-propylcarbazole; tera-cyanoquinodimethane

\section{Introduction}

Polymer-based electronic devices have been a popular research area in recent decades due to their unmatched properties, such as light weight, flexibility, low cost, scale-ability, low-temperature processing, tenability, etc. [1-4]. As a result, these devices are an excellent choice for light-emitting diodes, solar cells, low-cost RFID, sensors, and many other electronic devices [5-8]. For a number of applications, such as mobile phones, smart watches, and other electronic devices, low-cost and flexible memory devices are essential $[9,10]$. Therefore, polymer-based memory devices, compared to Si-based memory devices, represent a new trend that not only exploits the reported advantages of polymer, but also improves the storage capacity of memory space for future disposable electronic devices [10].

For this purpose, many semiconducting polymer materials have been previously reported to show capacitive, resistive, and transistor-based memory effects; among these, carbazole-containing materials (e.g., poly-N-vinylcarbazole, PVC) are gaining considerable attention [11-13]. The observed resistive memory response of PVK thin film is accounted due to the change in the electrical resistivity as a function of the applied electric field [14-16]. The possible mechanisms for resistive switching memory in conductive polymer can be approximately categorized into three types: reduction/oxidation, electronic, and thermal. In the reduction/oxidation type of resistive memory device, the ions are migrated towards the corresponding electrodes due to a series of electrochemical reactions, and hence form a low resistive $(\mathrm{ON})$ and high resistive (OFF) conducting path between electrodes under the influence of the applied electric field [14,17]. Similarly, for the electronic type of resistive memory device, the injected carriers are trapped (high resistance) and released (low resistance) during the charge transport process. Electronic charge trapping mechanisms 
are further classified as charge trapping inside the band gap, bulk charge trapping in the presence of the space charge, and charge trapping at metal-polymer interfaces. By comparison, in the thermal type of resistive memory device, the memory switching effects are originated by the formation and rupture of the conductive filamentary path initiated by the local Joule-heating effects $[14,18]$.

In the trapped space charge limited current model, it is generally accepted that both the positional and energetic traps have the capability to capture free charge carriers, which are distributed throughout the polymer layer and degrade the free carrier mobility (high resistance, OFF state), particularly at a lower operating voltage. In a higher applied electric field, many free carriers overcome the trap barrier potential to form a space charge, increasing the mobility and hence the conductivity (ON state) of the polymer thin film [15,19-23]. Such resistive ON and OFF behavior can be observed as hysteresis due to the film's currentvoltage characteristics. Therefore, the trapped space charge effect plays a vital role in defining the memory effect for many organic and polymer-based electronic devices [24].

Organic molecules, and particularly TCNQ-based charge transfer complexes, have a long history of use in memory and other electronic devices [25-28], and the highly stable and reliable memory response was noted for a $\mathrm{Cu} / \mathrm{Cu}-\mathrm{TCNQ} / \mathrm{Al}$ device, as reported by numerous researchers $[29,30]$. Therefore, in this study, a novel $\mathrm{Cu} / \mathrm{PEPC}-\mathrm{TCNQ} / \mathrm{Ag}$ device was fabricated and investigated. It was observed that the device shows a high rectification ratio $\left(\mathrm{I}_{\mathrm{ON}} / \mathrm{I}_{\mathrm{OFF}} \sim 100\right)$ with extended retention time, which is highly suitable for memory devices.

\section{Device Fabrication}

For the resistive memory device, a simple metal-polymer-metal like diode structure was fabricated at room temperature. For the active polymer layer, PEPC and TCNQ complex materials were selected, based on the advantages discussed above. The chemicals TCNQ (CAS number: 1518-16-7; molecular weight: 204.19; empirical formula (Hill Notation): $\mathrm{C}_{12} \mathrm{H}_{4} \mathrm{~N}_{4}$ ) and tetrahydrofuran (CAS number: 109-99-9; molecular weight: 72.11; empirical formula (Hill Notation): $\mathrm{C}_{4} \mathrm{H}_{8} \mathrm{O}$ ) were purchased from Sigma-Aldrich (Karachi, Pakistan), and PEPC was locally developed, for which detailed information can be found elsewhere $[12,13,28]$. The purchased chemicals were used without any further purification. The molecular structure of PEPC (1400 amu) and TCNQ is shown in Figure 1a,b, respectively. Generally, the doping of PEPC with TCNQ makes a charge transfer complex, where PEPC behaves as an electron donor, whereas the low-molecular-weight organic material TCNQ behaves as an electron acceptor [28]. The conductive TCNQ was obtained after successive processes of re-crystallization with acetonitrile solvent. Because both PEPC and TCNQ are soluble in tetrahydrofuran as an organic solvent, a solution was made between PEPC and TCNQ (4:1 ratio) with $8 \%$ by weight in the solvent tetrahydrofuran. Thin films of both PEPC and PEPC-TCNQ solution were deposited by the spin-coating method (1000 rpm, $30 \mathrm{~s}$ ) over $99.99 \%$ Cu substrate, separately. The thickness of the films was in the range of $500 \mathrm{~nm}-1.2 \mu \mathrm{m}$, and the average surface area of the films was in the range of $1.6-2.1 \mathrm{~cm}^{2}$. For another electrode, highly conductive silver paste was deposited onto the PEPC-TCNQ thin films. For characterization, three samples were fabricated for $\mathrm{Cu} / \mathrm{PEPC} / \mathrm{Ag}$ and $\mathrm{Cu} / \mathrm{PEPC}-\mathrm{TCNQ} / \mathrm{Ag}$ devices, and the median response (which was very close to the average response for most cases) among the three samples was selected for the further analysis that led to the conclusions. A schematic cross-section of the sample is shown in Figure 2. Using the hot probe method, it was observed that both PEPC and PEPC-TCNQ behave as a p-type semiconductor [28]. For forward bias current-voltage characteristics, the positive and negative terminal of the battery was connected to the top electrode $(\mathrm{Ag})$ and bottom $(\mathrm{Cu})$ electrode, respectively, for both devices, as shown in Figure 2. 


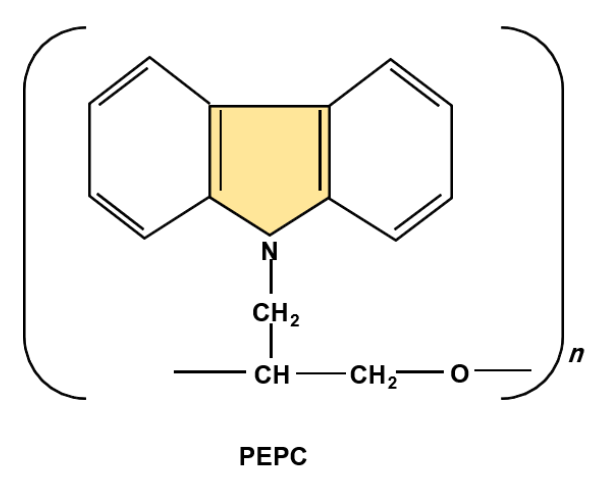

(a)

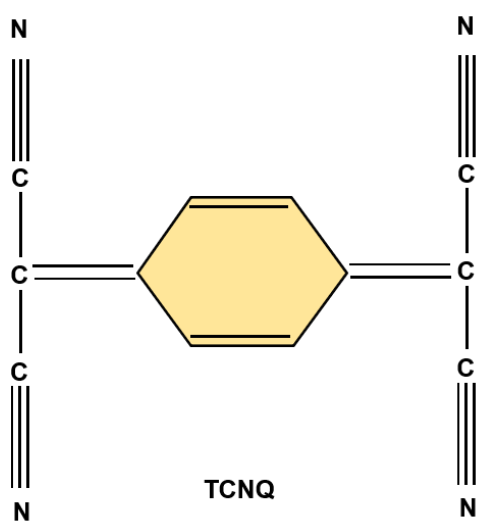

(b)

Figure 1. Molecular structure of (a) poly-N-epoxy-propylcarbazole (PEPC); and (b) 7,7,8,8-tetracyanoquino-dimethane (TCNQ).

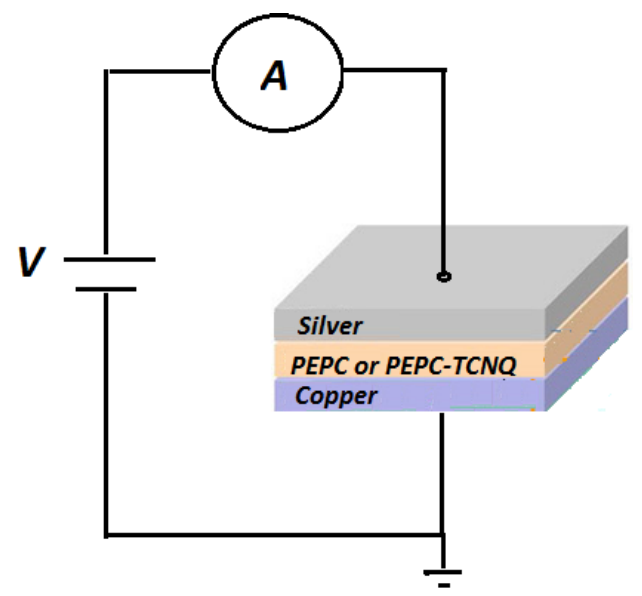

Figure 2. A cross-sectional view of a metal/polymer/metal diode fabricated using p-type PEPC, with or without TCNQ, as a Cu/PEPC/Ag- and Cu/PEPC-TCNQ/Ag-based memory device; for forward bias, the positive and negative terminals of the battery were connected to the top (Ag) and bottom $(\mathrm{Cu})$ electrodes, respectively, for both devices.

\section{Results and Discussion}

The current-voltage characteristics of both the $\mathrm{Cu} / \mathrm{PEPC} / \mathrm{Ag}$ and $\mathrm{Cu} / \mathrm{PEPC}-\mathrm{TCNQ} / \mathrm{Ag}$ devices were measured at room temperature, as shown in Figure 3. Because we were mainly interested in qualitatively determining and comparing the memory effects for the PEPC and PEPC-TCNQ devices, we measured the current-voltage hysteresis loop for both devices at a sweeping rate of $100 \mathrm{mV} / \mathrm{sec}$ for simplicity. The figure shows that both devices exhibited electrical switching effects in both forward and reverse cycles. In the first cycle, the applied voltage increased in the forward bias from zero to $3.25 \mathrm{~V}$ for the $\mathrm{Cu} / \mathrm{PEPC} / \mathrm{Ag}$ devices, and from 0 to $1.5 \mathrm{~V}$ for the $\mathrm{Cu} / \mathrm{PEPC}-\mathrm{TCNQ} / \mathrm{Ag}$ device, whereas in the second cycle, the applied voltage decreased in the forward bias from 3.25 and $1.5 \mathrm{~V}$ to zero voltage, respectively. The sweeping rate for both directions of the cycle was maintained at $100 \mathrm{mV} / \mathrm{sec}$ without any hold time. Both devices followed different current paths for different cycles, clearly demonstrating an electrical memory effect (transition from high resistance to low resistance) for both devices. The transition from high resistance state to low transition state was observed at $\sim 2.5 \mathrm{~V}$ for the $\mathrm{Cu} / \mathrm{PEPC} / \mathrm{Ag}$ device, whereas a sharp transition was observed at $1.5 \mathrm{~V}$ for $\mathrm{Cu} / \mathrm{PEPC}-\mathrm{TCNQ} / \mathrm{Ag}$. This result indicates that doping of PEPC with TCNQ improves the electrical bi-stability of the memory behavior. 


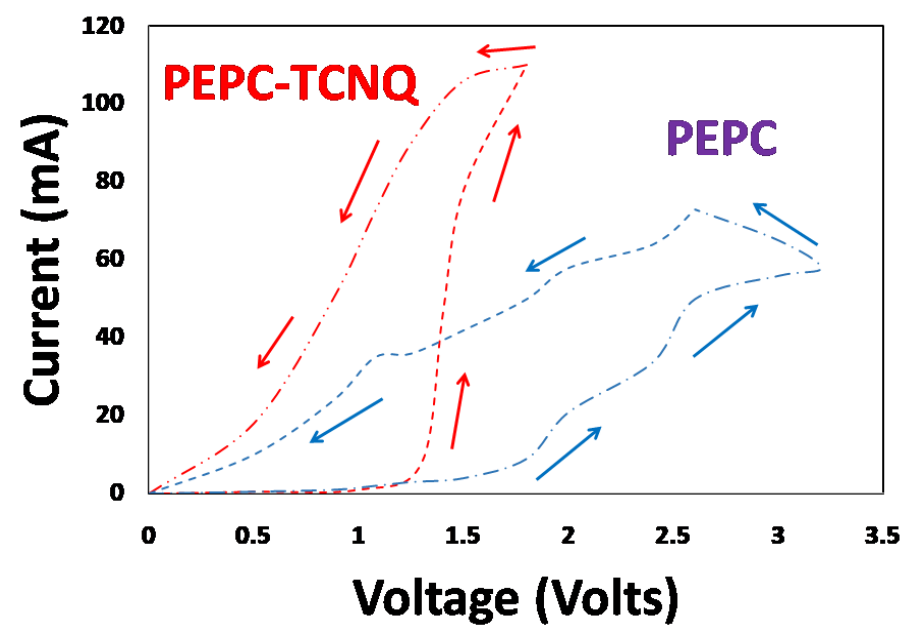

Figure 3. Current-voltage characteristics of $\mathrm{Cu} / \mathrm{PEPC} / \mathrm{Ag}$ and $\mathrm{Cu} / \mathrm{PEPC}-\mathrm{TCNQ} / \mathrm{Ag}$ diodes measured at room temperature, showing a typical memory hysteresis curve for both devices. The sweeping path in the figure is shown by the arrow directions.

To further investigate the likely switching mechanism of the $\mathrm{Cu} / \mathrm{PEPC}-\mathrm{TCNQ} / \mathrm{Ag}$ device, the $\ln$ (current) vs. $\ln$ (voltage) characteristics were further explored. Four welldefined charge transport regions were found as follows: (1) ohmic region; (2) trapped space charge region; (3) trapped filled voltage region (VTFL); and (4) trap-free space charge region [31-33], as shown in Figure 4. At an early stage, the devices follow ohmic response, leading to the trapped space charge limited current. This can be explained by the effects of mobility on charge concentration (holes) in the devices. With increasing voltage, the charge density increased. The sharp increase in the charge mobility with the hole density due to the trap filling was directly confirmed by [34]. By further increasing the voltage, the device reached a trapped-free region after passing through the trapped-filled voltage, as shown in Figure 3. The transformation of the trapped-space charge region to the trapped-free region is mainly accountable for the switching response of the $\mathrm{Cu} / \mathrm{PEPC}-\mathrm{TCNQ} / \mathrm{Ag}$ device.

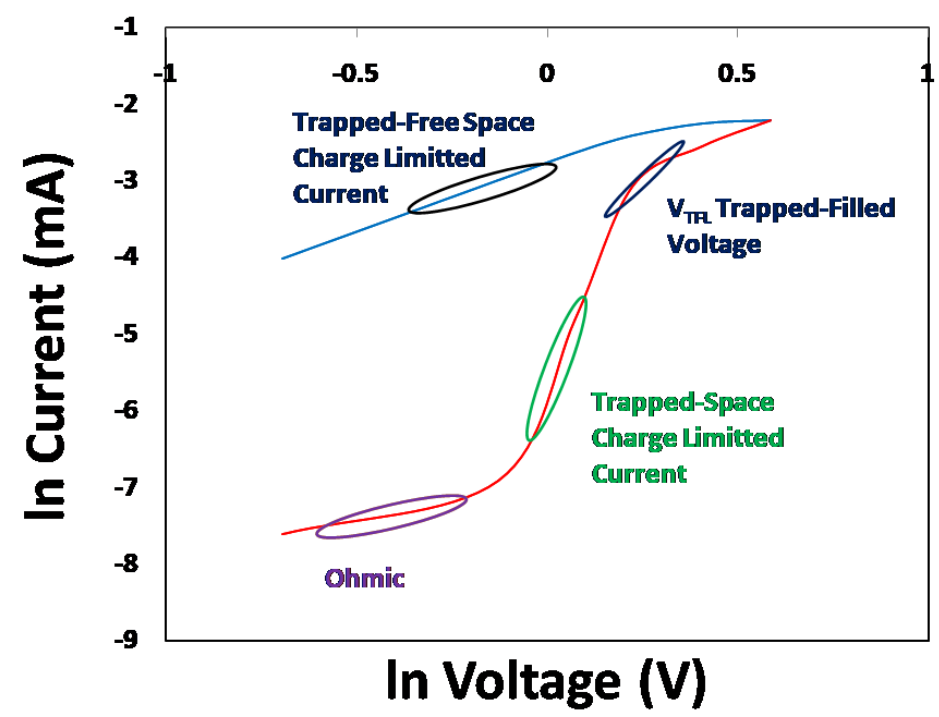

Figure 4. In Current vs. In Voltage characteristics of the Cu/PEPC-TCNQ/Ag diode, which clearly shows possible charge transport mechanisms as: (1) ohmic region; (2) trapped-space charge region; (3) trapped-filled voltage region; and (4) trapped-free space charge region.

The ON-OFF current ratio ( $\left.\mathrm{I}_{\mathrm{ON}} / \mathrm{I}_{\mathrm{OFF}}\right)$ is an important factor to define the performance of memory devices and can be estimated from the resistive hysteresis of the current-voltage response of memory devices. Because the resistive hysteresis is originated by the random 
trapping and de-trapping of charged carriers inside the bulk region of the polymer, the $\mathrm{ON}-\mathrm{OFF}$ ratio indicates the dynamic behavior of charged carriers. Hence, a high value of the ON-OFF current ratio indicates fast switching transition, whereas a low value of the ON-OFF current ratio reveals a slow switching transition inside the bulk region of the polymer. Figure 5 shows the ON-OFF current ratio for both $\mathrm{Cu} / \mathrm{PEPC}-\mathrm{TCNQ} / \mathrm{Ag}$ and $\mathrm{Cu} / \mathrm{PEPC} / \mathrm{Ag}$ memory devices as a function of applied voltage. The ON-OFF current ratio increases with increasing voltage up to a certain voltage with a maximum ON-OFF ratio; then, the given ratio begins to decrease as voltage increases further for both memory devices due to the complex dynamic behavior of deep-level traps. However, the domain of the voltages and the range of the ON-OFF current ratios are different for the two memory devices, as shown in the figure. The maximum and steeper $\mathrm{I}_{\mathrm{ON}} / \mathrm{I}_{\mathrm{OFF}}$ ratio $(\sim 100)$ are observed for the $\mathrm{Cu} / \mathrm{PEPC}-\mathrm{TCNQ} / \mathrm{Ag}$ device at nearly $0.85 \mathrm{~V}$, whereas the same maximum and broad $\mathrm{I}_{\mathrm{ON}} / \mathrm{I}_{\mathrm{OFF}}$ ratio $(23)$ is observed for the $\mathrm{Cu} / \mathrm{PEPC} / \mathrm{Ag}$ device at $1.4 \mathrm{~V}$. The figure clearly demonstrates that PEPC-TCNQ shows very fast memory switching with an excellent $\mathrm{I}_{\mathrm{ON}} / \mathrm{I}_{\mathrm{OFF}}$ ratio compared to the PEPC-based memory device [35]. Traps for PEPCTCNQ are simply defects or structural disorders in PEPC, which can be formed during the device fabrication process due to many known and unknown reasons, such as external or internal impurities and chemical defects [36]. It is generally accepted that the traps are energetically distributed between HOMO (highest occupied molecular orbital, valence band) and LUMO (lowest unoccupied molecular orbital, conduction band), and cause the electrical properties of polymer-based electronic devices to be degraded. Because the energy band gap of PEPC is much higher than the TCNQ energy band gap, TCNQ molecules may offer favorite sites for charge carriers hopping inside PEPC, which helps to improve the charge transport process at the applied voltage. Therefore, a visible improvement in currentvoltage characteristics was observed for the $\mathrm{Cu} / \mathrm{PEPC}-\mathrm{TCNQ} / \mathrm{Ag}$ device compared to the $\mathrm{Cu} / \mathrm{PEPC} / \mathrm{Ag}$ device.

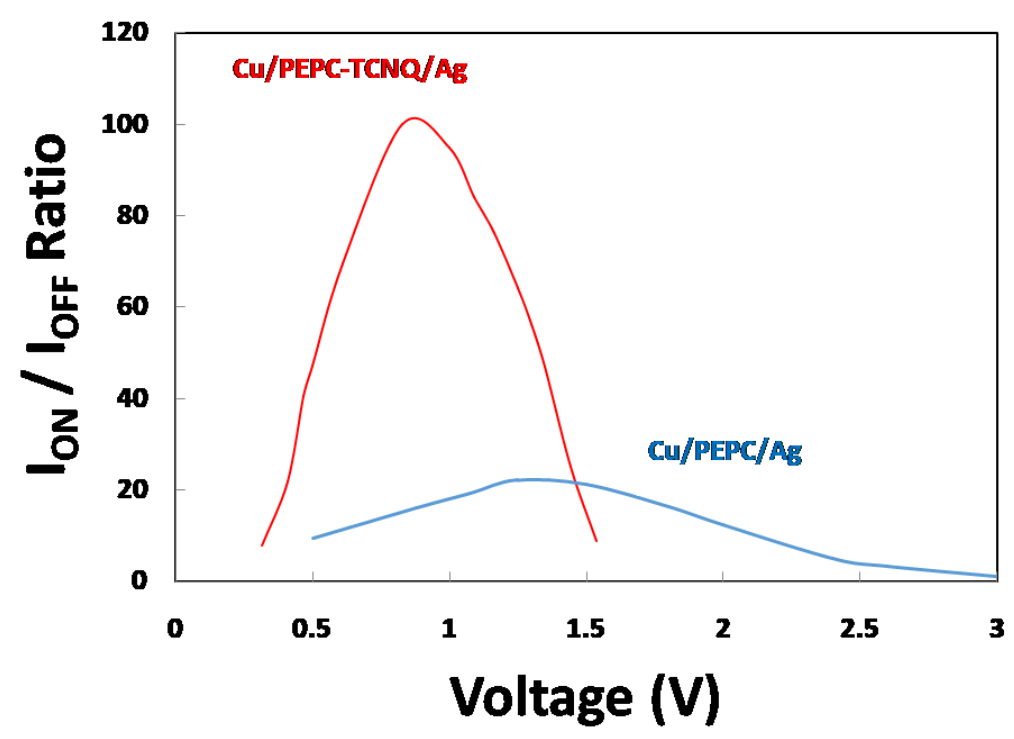

Figure 5. $\mathrm{I}_{\mathrm{ON}}$ and $\mathrm{I}_{\mathrm{OFF}}$ ratio $\left(\mathrm{I}_{\mathrm{ON}} / \mathrm{I}_{\mathrm{OFF}}\right)$ for $\mathrm{Cu} / \mathrm{PEPC} / \mathrm{Ag}$ and $\mathrm{Cu} / \mathrm{PEPC}-\mathrm{TCNQ} / \mathrm{Ag}$ devices as a function of applied voltage.

In the trapped-space charge region, when applied voltage is gradually increased from the ohmic region, the injected hole charges from the $\mathrm{Cu}$ electrode are caught by traps and are no longer available as free carriers, and, overall, the device offers high resistance (OFF state) to the flow of charges. By continuously increasing voltage in this region, traps are continuously filled and a stage is reached when nearly all traps are filled by injected carriers. Because filled traps do not play any further significant role in the charge transport mechanism, this stage is called the trapped filled voltage point. After this stage, both PEPC with or without TCNQ behaves like a trapped-free space charge limited current and offers 
very low resistance (ON state), yielding a higher $\mathrm{I}_{\mathrm{ON}} / \mathrm{I}_{\mathrm{OFF}}$ ratio, as shown in Figure 5 . However, the striking difference observed is that, for PEPC-TCNQ, the trapped-free region is achieved at a much earlier voltage (1.5 V) compared to PEPC (3.25 V), which clearly demonstrates that TCNQ improves the overall conductivity of PEPC for the ON state with fast switching for the $\mathrm{Cu} / \mathrm{PEPC}-\mathrm{TCNQ} / \mathrm{Ag}$ memory device.

Similar to the fast switching characteristics, the stability in terms of retention of the ON and OFF states of the memory device for a longer period is another important parameter required for the performance of polymer memory devices. Therefore, the retention $\mathrm{ON}$ and OFF state resistance was investigated, measured from the current-voltage characteristics. For this purpose, the samples were heated up to $60^{\circ} \mathrm{C}$ and held for $15 \mathrm{~min}$ to achieve thermal equilibrium. After thermal equilibrium, the resistance was measured for up to approximately 8 continuous hours $(480 \mathrm{~min}$ ) under the same laboratory environmental conditions. In addition, the temperature was continuously monitored to maintain it at $60{ }^{\circ} \mathrm{C}$ throughout the experiment for both devices. The output results are shown in Figure 6. Therefore, the marker points in Figure 6 correspond to the resistance of both memory devices in the ON/OFF states as a function of the same time interval. These resistance measurements were carried out in a very similar way to that discussed in Figure 3, but the resistances were calculated at $60^{\circ} \mathrm{C}(1$ volts $)$ as a function of ageing time. The figure clearly shows that both ON state (relatively low) and OFF state (relatively high) resistance demonstrate nearly negligible degradation for both devices, illustrating the excellent stability of the $\mathrm{Cu} / \mathrm{PEPC}-\mathrm{TCNQ} / \mathrm{Ag}$ - and $\mathrm{Cu} / \mathrm{PEPC} / \mathrm{Ag}$-based memory devices under the given conditions.

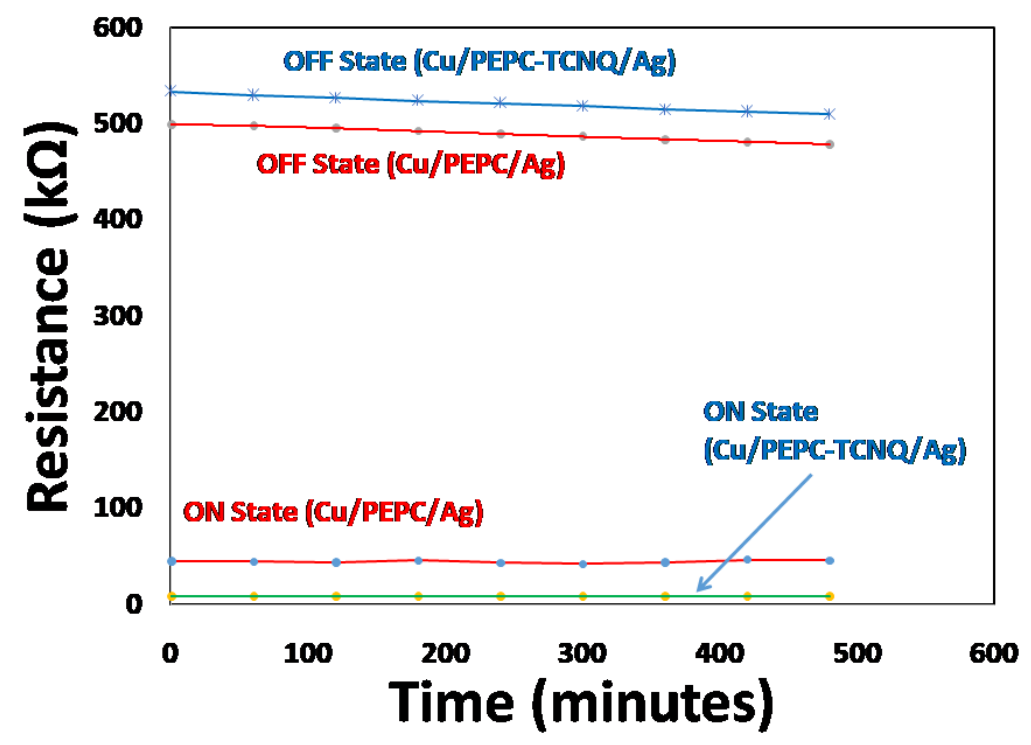

Figure 6. Degradation of $\mathrm{ON}$ state and $\mathrm{OFF}$ state resistance as a function of time for $\mathrm{Cu} / \mathrm{PEPC} / \mathrm{Ag}$ and $\mathrm{Cu} / \mathrm{PEPC}-\mathrm{TCNQ} / \mathrm{Ag}$ devices after heating and holding the sample at $60{ }^{\circ} \mathrm{C}$ for $\sim 1 \mathrm{~h}$ duration.

\section{Conclusions}

To investigate memory switching effects, the electrical characterization of a single layer memory device (metal-polymer-metal) containing PEPC doped with and without TCNQ charge transfer complexes was performed for $\mathrm{Cu} / \mathrm{PEPC} / \mathrm{Ag}$ and $\mathrm{Cu} / \mathrm{PEPC}-\mathrm{TCNQ} / \mathrm{Ag}$ memory devices. From the current-voltage characteristics, it was observed that both devices showed memory switching effects. However, the doping of PEPC with TCNQ improved the quick response of the memory device, resulting in a high $\mathrm{ON}$ and OFF ratio $\left(\mathrm{I}_{\mathrm{ON}} / \mathrm{I}_{\mathrm{OFF}} \sim 100\right)$. This memory switching effect may be due to the observed space charge limited behavior in the presence of trap distributions for both devices. Finally, both devices demonstrated a high degree of retention stability for the required memory operations. 
Author Contributions: Conceptualization, A.N.M.A.; resources, A.N.M.A. and K.S.K.; validation, A.N.M.A. and K.S.K.; writing-original draft, A.N.M.A.; writing-review and editing, K.S.K. All authors have read and agreed to the published version of the manuscript.

Funding: This research received no external funding.

Institutional Review Board Statement: Not applicable.

Informed Consent Statement: Not applicable.

Data Availability Statement: The data presented in this study are available on request from the author.

Conflicts of Interest: The author declares no conflict of interest.

\section{References}

1. Ying, S.; Ma, Z.; Zhou, Z.; Tao, R.; Yan, K.; Xin, M.; Li, Y.; Pan, L.; Shi, Y. Device Based on Polymer Schottky Junctions and Their Applications: A Review. IEEE Access 2020, 8, 189646-189660. [CrossRef]

2. Zheng, Y.; Fischer, A.; Sawatzki, M.; Doan, D.H.; Liero, M.; Glitzky, A.; Reineke, S.; Mannsfeld, S.C.B. Introducing PinMOS Memory: A Novel, Nonvolatile Organic Memory Device. Adv. Funct. Mater. 2020, 30, 1907119. [CrossRef]

3. Moiz, S.A.; Alahmadi, A.N.M.; Karimov, K.S. Improved Organic Solar Cell by Incorporating Silver Nanoparticles Embedded Polyaniline as Buffer Layer. Solid State Electron. 2020, 163, 107658. [CrossRef]

4. Moiz, S.A.; Alahmadi, A.N.M.; Aljohani, A.J. Design of Silicon Nanowire Array for PEDOT:PSS-Silicon Nanowire-Based Hybrid Solar Cell. Energies 2020, 13, 3797. [CrossRef]

5. Melling, D.; Martinez, J.G.; Jager, E.W.H. Conjugated Polymer Actuators and Devices: Progress and Opportunities. Adv. Mater. 2019, 31, 1808210. [CrossRef]

6. Lewis, J. Material Challenge for Flexible Organic Devices. Mater. Today 2006, 9, 38-45. [CrossRef]

7. Kruijne, W.; Bohte, S.M.; Roelfsema, P.R.; Olivers, C.N.L. Flexible Working Memory through Selective Gating and Attentional Tagging. Neural Comput. 2021, 33, 1-40. [CrossRef]

8. Yang, Y.; Ouyang, J.; Ma, L.; Tseng, R.J.-H.; Chu, C.-W. Electrical Switching and Bistability in Organic/Polymeric Thin Films and Memory Devices. Adv. Funct. Mater. 2006, 16, 1001-1014. [CrossRef]

9. Kim, S.-J.; Lee, J.-S. Flexible Organic Transistor Memory Devices. Nano Lett. 2010, 10, 2884-2890. [CrossRef] [PubMed]

10. Li, L.; Ling, Q.-D.; Lim, S.-L.; Tan, Y.-P.; Zhu, C.; Chan, D.S.H.; Kang, E.-T.; Neoh, K.-G. A Flexible Polymer Memory Device. Org. Electron. 2007, 8, 401-406. [CrossRef]

11. Wu, H.-C.; Liu, C.-L.; Chen, W.-C. Donor-Acceptor Conjugated Polymers of Arylene Vinylene with Pendent Phenanthro[9,10-d] Imidazole for High-Performance Flexible Resistor-Type Memory Applications. Polym. Chem. 2013, 4, 5261-5269. [CrossRef]

12. Moiz, S.A.; Karimov, K.S.; Ahmed, M.M. Effect of Gravity Condition on Charge Transport Properties of Polymer Thin Film Deposited by Centrifigual Method. Optoelectron. Adv. Mater. Rapid Commun. 2011, 5, 577-580.

13. Moiz, S.A.; Ahmed, M.M.; Karimov, K.H.S.; Mehmood, M. Temperature-Dependent Current-Voltage Characteristics of Poly-NEpoxypropylcarbazole Complex. Thin Solid Film. 2007, 516, 72-77. [CrossRef]

14. Chen, W.-C. Electrical Memory Materials and Devices; Polymer Chemistry Series; The Royal Society of Chemistry: London, UK, 2016. [CrossRef]

15. Saitov, S.R.; Amasev, D.V.; Tameev, A.R.; Kazanskii, A.G. A Simple Approach for Determination of Density of States Distribution in an Organic Photoconductor. Org. Electron. 2020, 86, 105889. [CrossRef]

16. Sun, Y.; Wen, D.; Sun, F. Influence of Blending Ratio on Resistive Switching Effect in Donor-Acceptor Type Composite of PCBM and PVK-Based Memory Devices. Org. Electron. 2019, 65, 141-149. [CrossRef]

17. Jeong, D.S.; Thomas, R.; Katiyar, R.S.; Scott, J.F.; Kohlstedt, H.; Petraru, A.; Hwang, C.S. Emerging Memories: Resistive Switching Mechanisms and Current Status. Rep. Prog. Phys. 2012, 75, 076502. [CrossRef] [PubMed]

18. Ling, Q.-D.; Liaw, D.-J.; Zhu, C.; Chan, D.S.-H.; Kang, E.-T.; Neoh, K.-G. Polymer Electronic Memories: Materials, Devices and Mechanisms. Prog. Polym. Sci. 2008, 33, 917-978. [CrossRef]

19. Majumdar, H.S.; Bandyopadhyay, A.; Bolognesi, A.; Pal, A.J. Memory Device Applications of a Conjugated Polymer: Role of Space Charges. J. Appl. Phys. 2002, 91, 2433-2437. [CrossRef]

20. Murari, N.M.; Hwang, Y.-J.; Kim, F.S.; Jenekhe, S.A. Organic Nonvolatile Memory Devices Utilizing Intrinsic Charge-Trapping Phenomena in an n-Type Polymer Semiconductor. Org. Electron. 2016, 31, 104-110. [CrossRef]

21. Bozano, L.D.; Kean, B.W.; Beinhoff, M.; Carter, K.R.; Rice, P.M.; Scott, J.C. Organic Materials and Thin-Film Structures for Cross-Point Memory Cells Based on Trapping in Metallic Nanoparticles. Adv. Funct. Mater. 2005, 15, 1933-1939. [CrossRef]

22. Moiz, S.A.; Ahmed, M.M.; Karimov, K.S. Estimation of Electrical Parameters of OD Organic Semiconductor Diode from Measured I-V Characteristics. ETRI J. 2005, 27, 319-325. [CrossRef]

23. Karimov, K.S.; Ahmed, M.M.; Moiz, S.A.; Babadzhanov, P.; Marupov, R.; Turaeva, M.A. Electrical Properties of Organic Semiconductor Orange Nitrogen Dye Thin Films Deposited from Solution at High Gravity. Eurasian Chem. Technol. J. 2007, 5, 109-113. [CrossRef] 
24. Xu, X.; Li, L.; Liu, B.; Zou, Y. Organic Semiconductor Memory Devices Based on a Low-Band Gap Polyfluorene Derivative with Isoindigo as Electron-Trapping Moieties. Appl. Phys. Lett. 2011, 98, 063303. [CrossRef]

25. Potember, R.S.; Poehler, T.O.; Cowan, D.O. Electrical Switching and Memory Phenomena in Cu-TCNQ Thin Films. Appl. Phys. Lett. 1979, 34, 405-407. [CrossRef]

26. Karimov, K.S. Transversal Tensity Resistive Effect in TEA (TCNQ)2 Crystals. Synth. Met. 1991, 44, 103-106. [CrossRef]

27. Karimov, K.S. Electrical Conductivity of TEA(TCNQ)2 Crystals under Uniaxial Tension and Compression. Solid State Commun. 1994, 89, 1029-1031. [CrossRef]

28. Ahmed, M.M.; Karimov, K.S.; Moiz, S.A. Temperature-Dependent I-V Characteristics of Organic-Inorganic Heterojunction Diodes. IEEE Trans. Electron. Devices 2004, 51, 121-126. [CrossRef]

29. Erlbacher, T.; Jank, M.P.M.; Ryssel, H.; Frey, L.; Engl, R.; Walter, A.; Sezi, R.; Dehm, C. Self-Aligned Growth of Organometallic Layers for Nonvolatile Memories: Comparison of Liquid-Phase and Vapor-Phase Deposition. J. Electrochem. Soc. 2008, 155, H693. [CrossRef]

30. Zhang, Q.; Kong, L.; Zhang, Q.; Wang, W.; Hua, Z. The Effect of Heat Treatment on Bistable Ag-TCNQ Thin Films. Solid State Commun. 2004, 130, 799-802. [CrossRef]

31. Rose, A. Space-Charge-Limited Currents in Solids. Phys. Rev. 1955, 97, 1538-1544. [CrossRef]

32. Campbell, A.J.; Bradley, D.D.C.; Lidzey, D.G. Space-Charge Limited Conduction with Traps in Poly(Phenylene Vinylene) Light Emitting Diodes. J. Appl. Phys. 1997, 82, 6326-6342. [CrossRef]

33. Moiz, S.A.; Younis, W.A.; Yilmaz, K.S.K.E.-F. Space Charge-Limited Current Model for Polymers. In Conducting Polymers; Khan, I.A., Ed.; IntechOpen: Rijeka, Croatia, 2016; p. 5. [CrossRef]

34. Toman, P.; Menšík, M.; Bartkowiak, W.; Pfleger, J. Modelling of the Charge Carrier Mobility in Disordered Linear Polymer Materials. Phys. Chem. Chem. Phys. 2017, 19, 7760-7771. [CrossRef] [PubMed]

35. Shah, M.; Karimov, K.S.; Ahmad, Z.; Sayyad, M.H. Electrical Characteristics of A1/CNT/NiPc/PEPC/Ag Surface-Type Cell. Chin. Phys. Lett. 2010, 27, 106102. [CrossRef]

36. Kadashchuk, A.; Weiss, D.S.; Borsenberger, P.M.; Ostapenko, N.; Zaika, V.; Skryshevski, Y. Effect of Extrinsic Traps on Thermally Stimulated Luminescence in Molecularly Doped Polymers. Synth. Met. 2000, 109, 177-180. [CrossRef] 